\title{
O todo e as partes - a forma ensaio e seu significado sociológico no pensamento de Georg Simmel e Walter Benjamin.
}

\author{
Wanderson Barbosa dos Santos ${ }^{1}$ \\ Recebido em março de 2021 \\ Aceito em junho de 2021
}

\begin{abstract}
RESUMO
Este artigo aborda sociologicamente a questão da forma ensaística nas obras de Georg Simmel e Walter Benjamin e seu papel para a interpretação do moderno. Em Simmel o ensaio incorpora a dinâmica dualista de sua sociologia, em razão de propor no confronto do duplo-olhar, um movimento entre interioridade e exterioridade. Benjamin propõe uma apresentação filosófica que se dedique ao movimento das ideias. Nesse sentido, se posiciona de forma crítica às tentativas da ciência organizada em cristalizar o conhecimento no estatuto da fórmula. Da plasticidade da forma ensaística, sublinha-se as afinidades eletivas da forma do ensaio como meio de exposição de pensadores como Simmel, Benjamin, Siegfried Kracauer e Norbert Elias. O conceito que congrega os autores mencionados é o de constelação. A constelação indica uma linhagem intelectual que herda do pensamento simmeliano um procedimento adotado em investigações socio-filosóficas sobre a modernidade.
\end{abstract}

Palavras-chaves: Ensaio; Constelação; Georg Simmel; Walter Benjamin; Norbert Elias.

The whole and the parts - the essay form and its sociological meaning in
Georg Simmel's and Walter Benjamin's thought

\begin{abstract}
This article examines sociologically the question of the essayistic form in the works of Georg Simmel and Walter Benjamin and their role in the interpretation of the modern. In Simmel, the essay incorporates the dualistic dynamics of his sociology because it proposes a movement between interiority and exteriority in the confrontation of the double-look. Benjamin proposes a philosophical presentation that is dedicated to the movement of ideas to critically position the attempts of organized science to crystallize knowledge in the formula's statute. From the plasticity of the essay form, we emphasize elective affinities between the form of the essay and others thinkers, such as Siegfried Kracauer and Norbert Elias. The concept that brings together the mentioned authors is that of constellation. The constellation indicates an intellectual lineage that inherits from simmelian thought a procedure adopted in socio-philosophical investigations about modernity.
\end{abstract}

Key-words: Essay; Constellation; Georg Simmel; Walter Benjamin; Norbert Elias.

\footnotetext{
${ }^{1}$ Sociólogo e doutorando pela Universidade de Brasília (UnB). Tem como campo de pesquisa temas como: sociologia dos intelectuais, história das ideias, teoria crítica da sociedade e sociologia da arte. E-mail: wanderson_santos@outlook.com.
} 


\section{A forma transparente do ensaio}

O ensaio é um tribunal, mas sua essência, o que decide sobre seu valor, não é, como no sistema, a sentença, e sim o processo de julgar.

Georg Lukács, Sobre a essência da forma do ensaio.

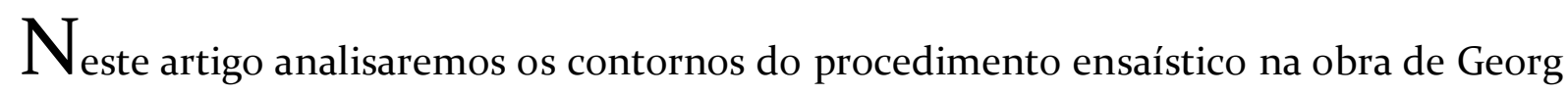
Simmel e Walter Benjamin. A ideia central, portanto, é compreender sociologicamente como a forma ensaística contribui para entendermos os projetos intelectuais dos autores tal como nos orientam no sentido de uma caracterização dos programas socio-filosóficos de interpretação do moderno. Desse ponto de vista, buscamos apresentar como a forma ensaio nas obras de Simmel e Benjamin alicerçam um procedimento de crítica moderna. Entendido como uma forma, o ensaio assume os contornos de crítica nos escritos de Simmel e Benjamin, na medida em que, reabilita noções como experiência, superfície e subjetividade, inserindo-as numa noção de constelação (configuração no sentido conferido por Elias em $O$ processo civilizador). Em poucas palavras: o ensaio de interpretação conduz o intelectual para uma compreensão da realidade em seu movimento, uma leitura contemplativa das transformações sociais. O conceito filosófico de constelação de Simmel e Benjamin, aproxima-se da ideia de configuração que Elias (1994) apresenta em O processo civilizador.

Antes de iniciarmos a reflexão propriamente dita, vale apresentar de forma esquemática os caminhos de uma definição da deia de ensaio. Recorremos aos escritos de Michel de Montaigne (2016) para situarmos contornos históricos do ensaio e do ensaísta. Nos volumes que compõe os Ensaios, Montaigne (2016) dá corpo a um novo gênero literário. $O$ ensaio se dedica a uma exposição das ideias sem o compromisso sistemático e aprofundado dos tratados intelectuais. O ensaio se satisfaz com o caráter impermanente de sua apresentação, não é o gênero adequado para verdades imutáveis, sendo inconciliável com o dogma. Na tradição de pensamento que se inicia com os escritos de Montaigne, cabe ao pensador conhecer o mundo na mesma medida em que ele passa a se conhecer, analisar o exterior de forma paralela em que se olha e se interpreta. 
Do duplo-olhar que tanto mira para o exterior, como contrasta com o interior, que se origina o procedimento do ensaísta. No texto dos Ensaios (2016) manifesta-se de forma orgânica o modo como se entrelaçam as dimensões da experiência particular e seu confronto com as ideias do mundo: trata-se da reabilitação de um conceito filosófico de experiência ${ }^{2}$. Nesse sentido, os Ensaios revelam a medida de seu autor. Montaigne alimenta sua escrita de suas próprias experiências, mas também daquilo que absorve do patrimônio literário mundial. Em seu encontro com a história não visa somente os grandes feitos, as espetaculares realizações humanas. Ele direciona sua lupa para a experiência dos personagens privados, marginais, contraditórios, incômodos, vergonhosos, visando tatear suas visões de mundo. A escrita do ensaio, portanto, apresenta um caminho de formação individual, pois indica os percursos de formação intelectual do escritor. O ensaio nessa particularidade clássica se assume como um gênero para a formação e desenvolvimento da personalidade. Com tal característica, a forma ensaio que se origina em Michel de Montaigne, se alinha a uma noção de cultivo e valorização da experiência que torna potente o exercício da interpretação do mundo. Da mesma maneira que o pintor de paisagem se volta suas energias para a composição totalizante do seu horizonte, o ensaísta visa apresentar seu mundo pela palavra. Sendo a palavra seu refúgio mais íntimo, o ensaísta muitas vezes foi confundido com o artista, pois sua atividade se define também pela plasticidade com que tateia seu objeto.

Nietzsche, em seu livro de 1872 , intitulado $O$ nascimento da tragédia, alude a tal procedimento do ensaísta, relacionando-o a arte. Seu argumento se estrutura a partir de uma crítica ao seu tempo, em específico, ao papel da racionalização na dominação da escrita científica. Para ele, o ensaio, reivindica seu atributo plástico de apropriação da palavra semelhante ao artista e, nesse aspecto, rompe com a perspectiva excessivamente racionalizada da escrita acadêmica moderna. Nesse sentido, o ensaísmo escapa dos contornos limitantes e restritivos da organização científica. Há, no livro de Nietzsche, uma complexa ideia do ensaio como unidade entre vida e arte. $\mathrm{O}$ ensaio se apresenta como em parte poesia, na medida em que tenta dar corpo a harmonia do movimento da

\footnotetext{
${ }^{2}$ Numa síntese do comentário anterior, destacamos a seguinte passagem presente nos Ensaios: "Em suma, todo este ensopado de frases aqui jogadas algo confusamente constitui uma espécie de registros das experiências de minha vida." (MONTAIGNE, 2016, p. 993).
} 
vida e cultura e, por outro lado, uma arte que se alimenta do olhar para a história. Como alternativa para o problema do declínio do espírito da época, Nietzsche defende uma escrita viva e criativa alicerçada em vivências situadas "sobre o terreno da arte" (NIETZSCHE, 2007, p. 13).

Numa caracterização das virtudes do ensaísta, frequentemente se defende sua aproximação com formas de expressão artística. O ensaísta captura tal atmosfera das experiências literárias e as traduz num texto de fronteira. Sua situação de fronteira devese ao fato dele dialogar organicamente com a literatura e as artes, tal como a ciência visa interpretar a natureza. De Montaigne a Nietzsche o ensaísmo forma sua característica de um gênero livre. Stefan Zweig (2013) em seu comentário biográfico sobre Montaigne, acentua a condição da liberdade espiritual presente nas formulações dos Ensaios. Para ele, Michel de Montaigne encarna uma postura de enfrentamento do intelectual diante do mundo. O ensaísta é o desafiante curioso que examina o mundo buscando dissecar a história da cultura. Para Zweig: "o patrono de todos os livres-pensadores do mundo" (ZWEIG, 2013, p. 28).

No exercício do livre-pensamento, o ensaísta organiza suas experiências numa prosa viva. A subjetividade funciona como um filtro para o exame da cultura que o rodeia. No entanto, tal postura diante do mundo não significa um mergulho profundo numa espécie de subjetivismo atomista. Ao contrário, o caráter impermanente do texto ensaísta reflete de forma translúcida o confronto entre o eu e o mundo. Deixa-se ver na mesma medida em que objetiva expor o outro.

De sua origem em Montaigne aos desdobramentos filosóficos do ensaísmo, o gênero foi constantemente repensando por outros autores. Tal como exposto em suas condições de um gênero de fronteira, o exercício do ensaísmo de fato se expressa de forma maleável, pois o próprio ensaísta deve negar uma definição rígida de sua atividade intelectual. Por esse motivo, muitos autores não se contentaram em escrever ensaios, mas dedicaram-se a escrever sobre o ensaio. É o caso de Lukács que em carta de 1910 para seu amigo Leo Popper fornece um novo vigor para a discussão teórica a respeito do ensaio.

Para Lukács (2014) o ensaio se posiciona diante da vida com o mesmo gesto da arte. Não importa a expressão sistemática, mas sim, o processo de julgamento exposto 
pelo ensaísta. Vale lembrar que Lukács faz um balanço original de ensaístas clássicos e modernos, tal como: Platão, Montaigne, Lessing, Wickelmann, Burckhardt e Kierkegaard. Na carta de 1910, o filósofo defende o ensaio como uma forma de arte. Uma forma de arte que está municiada por duas coisas: em primeiro lugar por um conceito enfático de crítica, em seguida por uma postura de acolhimento para um conjunto de experiências intelectuais a serem interpretadas como mote para a compreensão do mundo. Embora encontre tal afinidade entre o ensaio e a arte, Lukács observou um declínio do exercício do ensaísmo na modernidade 3 . Para ele, o ensaio moderno "perdeu o horizonte de vida", abrindo mão, portanto, dos conteúdos essenciais que dão corpo a forma ensaio: "Somente agora podemos assentar no papel as palavras iniciais: o ensaio é uma forma de arte, uma configuração própria e cabal de uma vida própria e completa.” (LUKÁCS, 2014, p. 50).

A forma ensaio que deriva das tradições de pensamento de Nietzsche e Lukács, como vimos, toma como estímulo as ideias de crítica como fonte para o exercício do ensaísmo. Num sentido filosófico a crítica reabilita o ensaio a partir das fontes primevas dos escritos de Montaigne. Sullivan (2015) aponta tal ambiguidade na origem da forma ensaio. Para ele, embora a origem do ensaio seja francesa, o ensaísmo como atitude intelectual desenvolveu-se na Inglaterra. Como postura intelectual, a ideia do ensaísmo se expande a partir do século XVIII, de acordo com Sullivan. Para ele, a história do ensaio tem seu desenvolvimento decisivo no palco da história moderna - em contraste a Lukács, para quem o ensaísmo tem uma herança mais ampla, estando presente desde os escritos de Platão. Tais discordâncias são importantes para notarmos a abrangência da discussão sobre o ensaísmo e sua persistência na reflexão intelectual.

Do ponto de vista desta introdução a questão do ensaio, vale mencionar ainda a reflexão de Max Bense (2014) sobre o tema. Em O ensaio e sua prosa, o autor analisa a

\footnotetext{
3 É evidente um sentimento de decadentismo da reflexão intelectual nos autores situados historicamente nas primeiras décadas do século XX. Contribui com o diagnóstico o forte impulso por especialização científica característica da modernidade. Ringer (2000) analisa tais reações do mandarinato alemão num certo "pessimismo" desses intelectuais diante das transformações da Alemanha industrializada. Sobre as preocupações referentes a especialização, sintetiza Ringer: "Assim, o axioma da doutrina mandarim era que a universidade devia dedicar-se a busca de uma verdade "total", filosófica. Não se devia abandonar essa busca em favor de resultados práticos imediatos; o ensino não deveria separar-se da filosofia." (RINGER, 2000, pp. 111-112).
} 
história do ensaísmo em sua relação com a estética. Portanto, trata-se de compreender quais os contornos dessa escrita que converge prosa e poesia. Max Bense usa a ideia de autor intermediário para situar uma forma de escrita posicionada entre a prosa e a poesia. Escritores como Lessing, Herder, Kierkegaard, Marx, Nietzsche, Sartre, Camus, Walter Benjamin, entre outros, apresentam um esforço para a criação de uma forma de pensar que congregue a poesia ao pensamento ${ }^{4}$. Max Bense define essa postura intelectual por meio das ideias de convicção e criação, na qual, o ensaísta sintetiza o diálogo orgânico entre as duas dimensões.

Podemos então admitir que entre a poesia e a prosa, entre o estado estético da criação e o estado ético da convicção, há um terreno intermediário que é digno de nota. De aspecto iridescente, oscilando numa ambivalência entre a criação e a convicção, ele se fixa na forma literária do ensaio. E com isso chegamos a nosso objeto. O ensaio é uma peça de realidade em prosa que não perde de vista a poesia. Ensaio significa tentativa (BENSE, 2014, p. 173, grifos do autor).

O ensaio, portanto, reflete os esforços, as tentativas, a experimentação intelectual. Max Bense defende o ensaio próximo de uma literatura experimental num sentido similar a ideia de experimento científico. O ensaísmo é uma tentativa de provar algo seguindo uma hipótese, no entanto, resguardado das pretensões universalizantes e definitivas da ciência. O ensaísta se contenta em se aproximar da arte para, a partir daí, expressar-se poeticamente. Do ponto de vista de Max Bense, o ensaio, o experimento, embora não se efetive como teoria, pode criar uma nova teoria a partir de sua apresentação, sobretudo no que Bense denomina como ensaísmo espiritual. O ensaísmo espiritual dedica-se aquilo que parece estranho à ciência, podendo tatear questões e criar novos objetos que, somente mais tarde, podem ser absorvidos pelo cânone científico. Por essa perspectiva, o ensaísmo é importante tanto por se afirmar como um gênero de liberdade intelectual, como também, por se mostrar como um texto de fundação, ou seja, um estilo de criação reflexiva.

\footnotetext{
4 Situando a ideia de pensamento e poesia, podemos fazer menção a caracterização que Adorno faz de Benjamin. Em sua forma de apresentação tão próxima do estilo literário diz Adorno em duas passagens interessantes: "O ensaio como forma consiste na capacidade de contemplar o histórico, as manifestações do espírito objetivo, a "cultura", como se fossem natureza. Benjamin tinha essa capacidade como poucos." (ADORNO, 1998, p.228) e "A sua ensaística consiste na abordagem de textos profanos como se fossem sagrados." (ADORNO, 1998, p. 230).
} 
Como vimos até aqui, o ensaio como forma e o exercício do ensaísmo compõe uma longa tradição intelectual. Ao mesmo tempo que se configura como um estilo livre, o ensaio também se insere em rigorosas tradições de exames filosóficos. Mesmo sendo uma forma que reconhece efemeridade, o ensaio pode conceder os substratos para construções perenes. Embora tenha uma identidade fronteiriça e desencaixada na história do pensamento, o ensaio é a forma que constrói as pontes entre o científico e o artístico.

Diante do exposto, nota-se as dificuldades para uma definição restrita da forma ensaio. Não é propriamente científico, tampouco essencialmente artístico. O ensaio é movimento, caminho entre mundos, escrita de fronteira. Jean Starobinski (2012), a respeito desta questão, aduz que o ensaio funciona como um jogo entre subjetividade e objetividade. Os objetos são examinados sob o filtro da experiência, no entanto, em frequente contraste com o mundo. Para Starobinski, o ensaísta, quando descreve o mundo, também se descreve - sendo seus textos, portanto, pinturas do eu.

A partir de agora veremos como podemos interpretar sociologicamente os escritos de Simmel e Benjamin por meio do mote do ensaísmo. A análise apresenta uma caracterização do procedimento intelectual dos autores. No caso de Simmel, o ensaísmo toma os contornos de uma dialética característica, ou seja, de um movimento particular entre exterioridade e interioridade. $\mathrm{O}$ duplo-olhar do ensaio simmeliano, nesse sentido, visa entrelaçar a dualidade entre o ponto de vista do sujeito na relação com sua rede de interações. No que diz respeito a Benjamin, o ensaísmo pode ser sintetizado numa palavra: interpretação movente. A ideia do procedimento ensaísta em Benjamin é dar sentido a apresentação dos objetos em seus movimentos imanentes, ou seja, cabe ao ensaísta realizar o acompanhamento das ideias, compreendendo seus passos, situandoas historicamente. O ensaio de interpretação em Simmel e Benjamin possuem algumas afinidades eletivas 5 . Indicamos o conceito de constelação como uma afinidade central entre os dois pensadores.

\footnotetext{
${ }^{5}$ A ideia de afinidades eletivas que fazemos referência no texto é a que deriva do romance de Goethe e que foi traduzida sociologicamente na obra de Max Weber em sua análise sobre o desenvolvimento do capitalismo tardio. A afinidade eletiva pode ser definida como um impulso à união, um encontro, uma afinidade espiritual, um sentimento partilhado, um ponto de equilíbrio que sugere estreita ligação. Tal
} 


\section{O todo e as partes: constelações sócio-filosóficas em Simmel e Benjamin}

Para compreender sociologicamente a forma ensaística de Simmel e Benjamin tomamos como fonte duas obras específicas. O primeiro texto é O estrangeiro, de 1908, escrito por Simmel. O segundo ensaio é o Prefácio crítico-epistemológico do livro $A$ origem do drama trágico alemão, de 1925, escrito por Benjamin. O que a escolha dos ensaios demonstra, naturalmente, não é uma afinidade temática entre as obras, fato este que não confunde nosso argumento na medida em que não visamos um exercício de comparação. Nosso olhar se volta para o exame do procedimento do ensaio. Por esse motivo, importa-nos entender como se estrutura o pensamento de Simmel e Benjamin. As obras supracitadas, quando analisadas detidamente, mostram, nas entrelinhas, retratos intelectuais de cada autor. Por meio do mote retrato intelectual, sustentamos que Simmel e Benjamin são exemplos no século XX do desenvolvimento do ensaísmo de interpretação. Tal concepção intelectual sugere uma sensibilidade para a reflexão teórica distinta da visão especializada da ciência.

Um autor contemporâneo a Simmel e Benjamin, Siegfried Kracauer, ensaiou uma espécie de retrato intelectual dos dois autores. Kracauer (2009) sublinha que há nos escritos de simmelianos a preocupação do olhar para contornos fragmentários da modernidade. Simmel realiza uma decomposição de seu objeto tateando cada parte para compreender a existência do todo nas partes. Embora tenha escrito obras de fôlego como a Filosofia do dinheiro de 190o, Kracauer destaca que para Simmel o texto não marca um fim, mas sim uma possibilidade de criação do novo: "O caminho do filósofo não termina nestas análises, mas passando por elas conduz a outras metas.” (KRACAUER, 2009, p. 244). Um pensamento que abre espaço para o cultivo de novas reflexões. Kracauer anota essa condição provocativa da filosofia de Simmel mostrando que, o interesse nas formas

concepção parece-nos interessante na arquitetura intelectual do estudo, na medida em que, permite compreender os programas de pesquisas de autores singulares sem recair em noções simplistas como de "influência" e "apropriação". As afinidades eletivas, portanto, contribuem para compreender o particular em seu encontro como o geral. 
de socialização revela um compromisso do autor com o conflito que marca a modernidade, ou seja, a relação entre indivíduo e sociedade.

O pensamento assistemático de Simmel, de acordo com Kracauer, situa uma própria dificuldade de classificação do pensamento desse autor. Embora se afirme como filósofo, ele transitou entre diversas outras ciências especializadas, tal como, a sociologia. O profundo interesse pelas manifestações da vida do espírito, levaram Simmel a propor interpretações sobre a vida moderna em seus ensaios. Kracauer destaca que um forte conceito de empatia alicerça os ensaios do autor, na medida em que por meio dele Simmel visa apresentar as conexões entre os fragmentos que compõem a sociedade.

Trata-se sempre de liberar o objeto de seu isolamento, examinando-os de todos os lados, até que não reconheçamos nele o aferrar-se de uma lei que está presente também lá para inseri-lo, de tal modo, em uma vasta rede de relações. (KRACAUER, 2009, p. 254).

Em síntese: "Pôr a nu os fios que envolvem os fenômenos", tarefa que Kracauer observa como lição constante dos ensaios de Simmel. A caracterização intelectual que Kracauer (2009) escreve sobre Benjamin carrega consigo uma convergência com a de Simmel, trata-se da ideia que, nos escritos benjaminianos apresentam-se uma exposição "estranha", somente compreendida por um compromisso enfático com a busca da dialética das essências. Benjamin não é um escritor de pensamento tradicional, para Kracauer, ele concretiza sua reflexão olhando para as ruínas, os fragmentos, os vestígios, as pistas deixadas para descrever filosoficamente a realidade a partir de sua origem. Como salienta Kracauer “o conhecimento nasce das ruínas”, e, no jogo dialético, toma forma concreta no pensamento de Benjamin (KRACAUER, 2009, pp. 284-285).

Nessa perspectiva, podemos notar que os escritos de Simmel e Benjamin possuem algumas características que tornam complexa a compreensão de seus desenhos teóricos, afinal, seus pensamentos possuem inúmeras camadas e nuances variando inclusive no olhar sobre o mesmo objeto. Tais características são: os atributos antissistemáticos de suas obras e a dimensão fronteiriça dos seus legados intelectuais. Seus ensaios podem ser lidos como fragmentos de um conjunto, partes de um todo, mas que, no entanto, não se realizam num sistema, visto que o processo nunca se encerra. 
Em outras palavras: cada contemplação do objeto, o exame de seu movimento, exige uma outra leitura. Ensaio é movimento, em Simmel e Benjamin, e tal procedimento convida o leitor para compreender os fenômenos em seu aspecto movente.

No ensaio $O$ estrangeiro (1908), Simmel indica os contornos gerais de seu procedimento ensaístico. Sua interpretação a respeito do tipo social do estrangeiro demonstra um exercício prático da descrição do ensaísta. Em Simmel o ensaio assume a dialética característica do duplo-olhar que mira tanto para a exterioridade, como para a interioridade. Assim, o ensaio de 1908 foi composto por um conjunto de impressões daquele sujeito posicionado de forma ambígua na sociedade, na medida em que está perto, mas ao mesmo tempo, permanece distante. Pertence embora não integre o conjunto. Ou seja, o estranho ${ }^{6}$.

Simmel (1992) visa compor seu ensaio com o olhar do estrangeiro. De seu ponto de vista, tal figura encarna a característica dualista: proximidade e distância, fixação e desprendimento, mobilização e desmobilização, envolvimento e indiferença, objetividade e subjetividade. Por meio do tipo social do estrangeiro, nesse sentido, Simmel objetiva a compreensão histórico-sociológica não apenas do modo como a sociedade enxerga aquele que não é familiar, mas também incrementa com as impressões deste ser social.

Como ensaio de interpretação, tal postura transparece o escritor. Em certo sentido, no ensaio $O$ estrangeiro a perspectiva é exposta a partir da ideia de unidade nas quais estão congregadas as experiências do não-familiar com as impressões daqueles com que ele inicia um processo de interação. Do mesmo modo que na experiência do estrangeiro unifica-se no dualismo característico da escrita de Simmel sobre a sociedade, a noção de unidade faz referência a um aspecto mais amplo constitutivo da sociabilidade do tipo social do estrangeiro. Tratam-se das disposições do estrangeiro em cultivar um tipo específico de interação. Simmel, portanto, tenta dar corpo as impressões de um

\footnotetext{
${ }^{6}$ A imagem de tipos sociais que se encontram no entre-lugar social foram abordadas de outras maneiras pela literatura e pela ciência. Sigmund Freud tenta congregar uma reflexão neste sentido em seu ensaio Das Unheimliche ( $O$ infamiliar). $\mathrm{O}$ autor se inspira no conto de E.T.A Hoffman $O$ homem de areia e aborda a origem da angústia provocada pela personagem não-familiar: "O infamiliar seria propriamente algo do qual sempre, por assim dizer, nada se sabe” (FREUD, 2019, p. 33).
} 
indivíduo inscrito em interações sociais de diferença. Ao ser social que tem sua existência fraturada pela perspectiva fronteiriça, cabe o cultivo de um olhar diferenciado para a sociedade. Sob as lentes do estrangeiro, expõe as consequências últimas da ideia de estranho (Fremde).

Cabe ao não-idêntico, isto é, ao estrangeiro, cultivar um olhar para a complexidade das formas de associação. Enquanto o familiar se acomoda com tudo aquilo que é habitual, geralmente permanecendo nas águas mais rasas a vida social, resta ao estrangeiro, para quem nada é cotidiano, realizar o mergulho profundo nos costumes e formas de vida que lhe são estranhas. No jogo da indiferença e envolvimento, o estrangeiro tem vantagem, na medida em que enxerga de longe, porém, também consegue diferenciar os detalhes das formas de interação. Tal disposição dualista, captada no ensaio de 1908, situa a experiência particular do ser social que une objetividade e subjetividade.

Nos sentidos que desejamos compreender o ensaísmo de Simmel, vale destacar que o estrangeiro, como uma imagem socio-filosófica, permite o ensaio do autor uma atemporalidade. O estrangeiro descrito não está delimitado no tempo e nem no espaço. Ele é o conceito movente, particular do argumento ensaísta. Para Simmel, portanto, vale como a unidade de impressões desse tipo social que serve como impulso originário para a observação das formas de interação. Para dialogarmos com a ideia de ensaio que mobiliza o presente trabalho, podemos defender que tal perspectiva ensaísta aponta para uma dimensão experimental da escrita de Simmel7.

O ensaio $O$ estrangeiro, por essa perspectiva, pode ser lido com um movimento experimental. Como indica Waizbort (2013) numa leitura sobre o ensaio em Simmel: “O

\footnotetext{
${ }^{7}$ No livro As aventuras de Georg Simmel, Leopoldo Waizbort (2013) sublinha alguns aspectos importantes do pensamento do filósofo berlinense. Waizbort argumenta que a cultura filosófica que orienta o pensamento de Simmel pressupõe uma atitude de apreensão do objeto em sua mobilidade particular, isto é, numa perspectiva de oposição atividade do dogma científico e numa aposta na plasticidade das coisas. O ensaio incorpora tal perspectiva filosófica, na medida em que: "movimento, subjetividade e experiência compõem a constelação do ensaio." (WAIZBORT, 2013, p. 35). O ensaísmo de Simmel tem como característica apresentar uma visada sobre o objeto, sem a intenção de esgotá-lo. Para Waizbort, o ensaio tem proximidade com a escrita de uma carta: "O característico da carta é seu caráter absolutamente subjetivo, e é isso que também encontramos no ensaio. O que o faz viver é essa tensão entre seus elementos subjetivos objetivos e por isso ele é a forma de apresentação da cultura filosófica." (WAIZBORT, 2013, p. 54).
} 
fragmento, o aforismo e mesmo o ensaio são formas que permitem um pensamento em movimento, work in progress." (WAIZBORT, 2013, p. 55). A partir do objeto mobilizado dá-se o contraste com o real. Ele não é final, mas sim um começo. Nesse aspecto o ensaísmo se mostra conflitiva com uma ideia de ciência, sobretudo se sob esta perspectiva se entender o exame exaustivo de hipóteses, refutações e universalidade de teses. No sentido que Simmel anota seu procedimento, o ensaio atua como um mapa que aponta para a morada das experiências.

Nas reflexões propedêuticas do Prefácio crítico-epistemológico do livro de 1925, Benjamin visa reabilitar o conceito de apresentação (Darstellung) na filosofia ${ }^{8}$. A apresentação ou exposição se propõe como um procedimento, na medida em que, por meio dela o pensador pode se dedicar à contemplação efetiva dos conceitos. A ideia de apresentação que Benjamin se refere, é a de movimento das ideias que atuaria na contraposição da imposição do sistema filosófico, da lógica matemática9. Nesse sentido, o filósofo propõe um pensamento antissistemático que seja capaz de contemplar a verdade. Benjamin (1991) dialoga fortemente contra o neopositivismo e o historicismo. Sua crítica se direciona a visão atomizada de tais perspectivas, sobretudo em sua síntese na ideia de representação. Nas teses do Prefácio há uma defesa da perspectiva da apresentação do movimento dos conceitos. Os conceitos, para Benjamin, carregam consigo uma memória histórica, isto é, são o resultado de um acúmulo de conhecimento, testemunhas de experiências.

\footnotetext{
${ }^{8}$ Sobre a questão da ideia filosófica de Darstellung estamos de acordo com Machado (2014): "O conceito de apresentação (Darstellung), ou ainda, exposição tem um papel central no contexto do prefácio. [...] Neste momento, trata-se de colocar o conceito de apresentação como determinante do método da filosofia mesma. Justamente por ser apresentação, o método filosófico para Benjamin deve diferenciarse tanto do procedimento matemático como de todo sistema construído lógica e dedutivamente." (MACHADO, 2014, p. 46).

9 Dessa crítica presente no livro de Benjamin se desdobra uma afinidade importante de Benjamin com outros pensadores da teoria crítica da sociedade, em específico, Theodor Adorno e Max Horkheimer. A crítica comum contra o sistema e a lógica matemática encontra-se presente na formulação de $O$ ensaio como forma, escrito por Adorno. Juntos, Adorno e Benjamin efetivam uma posição filosófica enfática em oposição ao positivismo e ao programa de pesquisa científico que se origina em Descartes (1596-1650). Em Max Horkheimer, um eco de tal cítrica pode ser visto em algumas teses do livro Eclipse da razão de crítica a primazia do pensamento neopositivista na ciência moderna: "De acordo com a filosofia do intelectual moderno, há apenas uma autoridade, a saber, a ciência, concebida como classificação de fatos e o cálculo de probabilidades. A afirmação de que a justiça e a liberdade são em si melhores que a injustiça e a opressão é cientificamente inverificável e inútil.” (HORKHEIMER, 2015, p. 32).
} 
O Prefácio de 1925 mostra de forma mais esquemática o procedimento de Benjamin. O autor alude que em sua alternativa filosófica ao sistema fechado, tal perspectiva assemelha-se ao ensaio esotérico (Essay esoterischen). O compromisso dessa forma ensaio é com a apresentação do movimento das ideias. Para Benjamin, a filosofia moderna abandona o compromisso com a verdade, em razão de afastar-se de tal perspectiva. A filosofia que emerge a partir de Descartes tem como pacto a cristalização e a redução do conhecimento à fórmula matemática. Contra o neopositivismo, Benjamin critica a intenção de retirar a reflexão científica do mundo, destacando na representação um fragmento deslocado da realidade.

Benjamin (1991) observou que a cristalização do conhecimento partia de um compromisso intrínseco com a reflexão dentro do sistema. Foi a partir de tal postura que se muda o sinal da questão: da apresentação para a representação. A representação isola os fragmentos da realidade sem a perspectiva de um momento de totalidade. De acordo com o autor, tal perspectiva leva a uma descaracterização da complexidade do objeto e um abandono por uma perspectiva de verdade. Para o pensamento da representação importa a transmutação da realidade numa formulação numérica, autonomizada de uma ideia de todo social. Um momento singular figurado como instante eterno. Benjamin critica tal postura como forma de apreensão de conhecimento e sugere no procedimento o ensaio uma alternativa.

A forma do ensaio esotérico, seguindo os passos de Benjamin (1991), incorpora o sentido pleno da ideia de apresentação das ideias, tal como, se configura como um procedimento de contemplação do movimento das ideias. Ao contrário da pretensão do sistema ao estabilizar a realidade no fragmento isolado, Benjamin defende como contraponto uma contemplação não-intencional em busca pela verdade. Para o autor “método é desvio" (BENJAMIN, 1991, p. 208). Machado (2014) sublinha um importante argumento ligado a ideia o jogo entre singularidade e totalidade: “A totalidade deve ser encontrada no singular. O universal não é considerado como algo puramente abstrato, mas concreto, pois ele se revela no singular." (MACHADO, 2014, p. 47).

Na impossibilidade de paralisar a realidade, portanto, Benjamin (1991) aposta no acompanhamento das ideias como procedimento do ensaísta. No Prefácio de 1925 tal reflexão emerge como uma crítica aos sistemas filosóficos modernos, mas também como 
um modo de insinuar os contornos de seu próprio pensamento. $\mathrm{O}$ importante conceito de origem (Ursprung), em certo sentido, sublinha tal perspectiva, pois da gênese dos conceitos Benjamin consegue romper com as teorias progressistas da história e, com olhar detido para o momento único, reabilitar o verdadeiro momento de rememoração para restaurar a experiência. Na origem estão as inscrições que tornam os conceitos únicos. Neste acompanhamento de seu movimento conceitual no palco da história, Benjamin sublinha a postura do pensador crítico.

Desta perspectiva presente no Prefácio, Benjamin defende que cabe ao ensaísta apresentar os conceitos na história conectando os fragmentos à totalidade. Embora o ensaísta possa tomar como mote para sua análise o fragmento, seguindo Benjamin, ele deve na exposição apresentar as mediações entre as partes e o todo. Esse pensador possui como tarefa encontrar as conexões das configurações da sociedade. No entanto, Benjamin era ciente da dificuldade da tarefa: a exposição do ensaio, assim, é sempre tentativa incompleta. Somente no sistema filosófico rígido a reflexão possui um fim. Ao ensaísta compete colecionar fragmentos e apresentá-los como formas efêmeras: “A verdade é a morte da intenção.” (BENJAMIN, 1991, p. 216).

Deste posicionamento anteriormente descrito, Benjamin visa estabelecer as bases do ensaísmo e congregá-lo com uma ideia enfática de crítica. Se olharmos para os Exposés presentes no trabalho das Passagens, Benjamin (2018) experimenta o procedimento filosófico apresentado no Prefácio de 1925, expondo uma interpretação movente.

No ensaio Paris, a capital do século XIX, Benjamin olha para a cidade visando compreender as transformações modernas e o impacto na paisagem urbana parisiense. Benjamin direciona seu olhar para a origem das passagens parisienses e toda sociabilidade que emerge no interior dessa construção arquitetônica. Paris como capital da modernidade funciona como um laboratório reflexivo para o ensaísta. Dentro do laboratório filosófico do autor, a imagem do flâneur é central para a compreensão do experimento. Na perambulação do flâneur Benjamin descreve as mudanças na capital francesa, o novo tipo de sociabilidade cultivada nas ruas, o caráter avassalador do capitalismo na arquitetura e a imposição de um espírito de liberdade. O conceito de flâneur é efêmero, modifica-se por todo ensaio benjaminiano. Se no início o seu 
caminhar é marcado pelo sentimento de distinção do homem que flutua sobre a multidão afirmando sua diferença, ao final da análise, o otimismo do personagem se dissolve na massa uniforme que toma conta das ruas da metrópole.

Como é conhecido, o escrito mencionado possui duas versões. A primeira de 1935 e a segunda de 1939. Entre as duas encontramos passagens sugestivas da própria composição do tipo social flâneur. Diz Benjamin em 1935: "Com o flâneur, a intelectualidade encaminha-se para o mercado." (BENJAMIN, 2018, p. 64). Acrescenta no texto de 1939: "O flâneur representa o arauto do mercado. Nesta qualidade ele é ao mesmo tempo o explorador e a multidão.” (BENJAMIN, 2018, p. 83). Tais acréscimos são significativos para o argumento, na medida em que sinalizam os movimentos contínuos do ensaísta. O autor acompanha os movimentos livres do objeto, sua exposição é o retrato de um momento que necessita sempre ser atualizado.

Considerando a tradição do ensaísmo, Simmel e Benjamin são autores importantes para compreendermos capítulos dessa história intelectual. O ensaio como tentativa, ensaio como experimento, ensaio como movimento originário das ideias, ensaio como escrita movente. O que permite a concretização da conexão entre o todo e as partes é o conceito de constelação que, como veremos a seguir, atua como uma afinidade eletiva decisiva entre o pensamento de Simmel e Benjamin. ${ }^{10}$

\section{Interpretação movente: figurações e constelações no exercício ensaísta}

O ponto comum da tradição intelectual ensaísta que nos referimos são os conceitos de constelação e configuraçãon ${ }^{11}$. Tais conceitos são indícios de afinidades eletivas entre o ensaísmo e a produção sociológica alemã, em especial a de Norbert Elias.

${ }^{10}$ Do que foi exposto até aqui, podemos observar uma outra afinidade eletiva entre os programas de pesquisa dos dois autores. Trata-se do uso de tipos sociais. Tais personagens, como o estrangeiro e o flâneur, atuam como mediação para a descrição de uma ideia em movimento nos ensaios de Simmel e Benjamin.

${ }^{11}$ Sobre a ideia de constelação no pensamento de Simmel, Waizbort (2013) argumenta que ela se encontra presente na ideia de cultura filosófica e na adoção ensaio por parte do autor: "A própria ideia de constelação é algo que parece estar intimamente ligada ao ensaio. Em Simmel essa ideia aparece recorrentemente e isso foi incorporada pela crítica, pela sociologia e pela filosofia no curso do século (pois a ideia de "constelação" é uma ideia "ensaística”, ligada a liberdade do ensaio)." (WAIZBORT, 2013, p. 70 ). 
Vinculada a este último objetivo, iremos repensar a crítica comum de superficialidade da prosa ensaística. A ideia principal não é negar a ideia de superfície, mas sim, pensá-la como dessa noção emerge um procedimento, isto é, uma forma de apreender a realidade reabilitado no desenvolvimento do ensaísmo contemporâneo. A segunda crítica que visamos retrabalhar é a referente a ideia de subjetivismo da atividade do ensaísta. Em contraponto a tal perspectiva, defendemos que, no exercício do ensaísmo, a subjetividade e o olhar interior atuam como um ponto de partida para o confronto das impressões do escritor com o mundo objetivo. Nesse sentido, o ensaísta escapa a dimensão de puro subjetivismo ao apostar numa interpretação movente das ideias, dos conceitos e das formas.

É conhecida entre os estudiosos da obra de Simmel a declaração dita em 1918 que ele não deixaria como legado herdeiros intelectuais. Para ele, sua herança intelectual, não seria repassada como uma fortuna a uma única pessoa, mas sim, como moedas, sua herança seria dividida em diversas partes a ponto de ser impossível identificação de sua raiz comum. A pesquisa sociológica da história intelectual tem encontrado algumas raízes comuns entre pensadores posteriores a Simmel. A afinidade eletiva entre o filósofo berlinense e Walter Benjamin, que defendemos neste artigo, é apenas um ramo da herança simmeliana.

Semelhante ideia encontra-se num artigo de Leopoldo Waizbort (2001) quando sugere que, elementos fundantes da sociologia de Norbert Elias se encontram, originalmente, nos escritos de Simmel ${ }^{12}$. A ideia de uma sociologia das formas de interação, do confronto e dos processos de configuração, conecta Simmel e Elias num programa de pesquisa de uma sociologia dos processos. Como sublinha Waizbort, na obra de Elias, a ideia de uma sociologia do confronto está alicerçada num entendimento de que as interações (Wechselwirkung) são momentos sempre em movimento, isto é, efêmeros: "Daí o caráter fundamentalmente processual das sociologias de Simmel e

\footnotetext{
${ }^{12}$ Para Waizbort (2001), em certo sentido, Elias formaliza a sociologia simmeliana, levando adiante seu programa de pesquisa e desenvolvendo sua proposta de sociologia do confronto no exame empírico: "O que salta aos olhos, ao lermos Elias, é como suas formulações estão na continuidade a mais estreita com o pensamento simmeliano. Sou inclusive tentado a dizer que a contribuição de Elias está em formalizar, no conceito de figuração e suas consequências, a concepção que está presente nas análises de Simmel, embora não apareça, então, sob tal terminologia." (WAIZBORT, 2001, p. 102).
} 
Elias: como o movimento é aqui fundamental, eles têm sempre em vista processos, e não estados fixos e acabados." (WAIZBORT, 2001, p.105). A parte da herança simmeliana que coube a Elias encontra-se no conceito de configuração.

Num ponto decisivo da obra O processo civilizador, Elias (1994) defende que o conceito de configuração atua como alternativa decisiva para a compreensão sociológica do desenvolvimento da sociedade. O conceito de configuração, portanto, permite ao pesquisador observar o mundo empírico e compreender mudanças estruturais de longo prazo. A configuração se insere no horizonte sociológico de forma decisiva a ideia de processo, que por sua vez, permite uma apreensão da relação entre o indivíduo e as estruturas sociais. Para Elias (1994) toda mudança se estrutura em outras formas de configuração ${ }^{13}$.

Se olharmos para a ideia análoga presente na obra de Simmel (1992), isto é, a constelação (Konstellation), de fato, o princípio se mostra semelhante. No ensaio sobre O estrangeiro, Simmel menciona o conceito de constelação como sinal de expressão das relações entre o indivíduo e grupo, visto que, a ideia congrega as perspectivas de distância e proximidade, indiferença e identidade num movimento da totalidade das interações. O procedimento de estudo das formas de interação (Wechsekwirkungsform) simmeliano, portanto, contribue para o cultivo de um olhar sociológico mais sensível para as nuances dos confrontos entre indivíduo e estrutura social. Constelação ou configuração são conceitos-chave e fundantes para a sociologia dedicada a compreensão dos processos históricos.

Nessa tradição de pensadores alemães a qual nos referimos, o ensaísmo adentra como uma forma de exposição não-sistemática das mudanças e dos processos. A apresentação do todo configurado (da constelação) perpassa pelo reconhecimento do caráter mutável das formas sociais, tal como, da fina tessitura que compõe a rede de interdependência social. Em certo sentido, podemos inserir Walter Benjamin nesta

\footnotetext{
${ }^{13}$ Sobre o conceito de configuração em Elias: "O conceito de configuração foi introduzido exatamente porque expressa mais clara e inequivocamente o que chamamos de "sociedade" que os atuais instrumentos conceituais da sociologia, não sendo nem uma abstração de atributos de indivíduos que existem sem uma sociedade, nem um "sistema" ou "totalidade" para além dos indivíduos, mas a rede de interdependências por eles formada.” (ELIAS, 1994, p. 249)
} 
discussão ${ }^{14}$. Benjamin apropria-se de modo semelhante da ideia de constelação no Prefácio do livro a Origem do drama trágico alemão.

No Prefácio do livro de 1925, Benjamin (1991) sugere a constelação com um modo de conexão entre as ideias: "As ideias são como constelações eternas" (BENJAMIN, 1991, p. 215). As ideias relacionam historicamente do mesmo modo que as estrelas configuram as constelações. Benjamin sublinha que, dada sua dispersão natural, cabe ao filósofo reencontrar as conexões essenciais no universo da linguagem, especificamente, visando encontrar o caráter original do conceito. Para Benjamin, tal composição constelacional permite a apreensão histórica das ideias, bem como a compreensão dos processos e do movimento das ideias. Em poucas palavras: a constelação se concretiza como uma postura que visa articular a rede de conhecimento, escavando as experiências históricas presentes nas ideias.

Tal ponto de vista teórico auxiliou Benjamin a escapar das teorias deterministas do historicismo e de uma visão progressista da história. Os herdeiros de Simmel usam a fortuna intelectual de forma distinta. Enquanto Elias insere a ideia constelacional em seu procedimento de investigação dos processos de mudança estrutural e das formas de interação, Benjamin traduz a ideia simmeliana numa teoria de recuperação das experiências históricas que constituem as ideias. A herança comum pode ser sintetizada na ideia de que, as configurações, são efêmeras e devem ser visadas ao longo de seus processos na história.

Estabelecidas algumas notas sobre a ideia de movimento, sob o prisma da análise dos conceitos de constelação e configuração, e a afirmação de uma linhagem de pensadores que se colocam na herança intelectual de Simmel, passemos agora para uma breve discussão sobre as críticas ao procedimento ensaísta. Embora a atividade do

\footnotetext{
${ }^{14}$ Adorno (2003) anota uma interessante ligação entre a ideia de configuração e o procedimento do ensaísta: “Todos os seus conceitos devem ser expostos de modo a carregar os outros, cada conceito deve ser articulado por suas configurações com os demais. No ensaio, elementos discretamente separados entre si são reunidos em um todo legível; ele não constrói nenhum andaime ou estrutura. Mas, enquanto configuração, os elementos se cristalizam por seu movimento. Essa configuração é um campo de forças, assim como cada formação do espírito, sob o olhar do ensaio, deve se transformar em um campo de forças." (ADORNO, 2003, p. 31).
} 
ensaísta acumule um conjunto grande de objeções, nos deteremos a apenas duas delas, a saber: a acusação de superficialidade e de exercício intelectual puramente subjetivista. Em O ensaio como forma, Adorno (2003) sublinha as "difamações" que circundam a atividade do ensaísta. Por um lado, a alegada irracionalidade defendida pelos representantes da ciência organizada. Por outro lado, a sugestão que o ensaísta é o resultado decaído de um tipo de literatura. O ensaio para Adorno está no âmbito da interpretação sensível dos objetos e na contramão das tentativas de pura classificação e mutilação do conhecimento. O ensaísta, antes de tudo, tem como objetivo "desvendar o objeto" por meio de uma fértil fusão entre literatura, crítica e experiências. O ensaio é uma forma que atua na mediação dos fragmentos, uma tentativa de interpretação que toma como princípio a experiência e as impressões sobre uma configuração.

O ensaio pensa em fragmentos uma vez que a própria realidade é fragmentada; ele encontra sua unidade ao buscá-la através dessas fraturas, e não ao aplainar a realidade fraturada. [...] A descontinuidade é essencial ao ensaio; seu assunto é sempre um conflito em suspenso. (ADORNO, 2003, p. 35, grifos nossos).

Dos sentidos encontrados em sua forma, o ensaio assume a superfície como ponto de partida para a apreensão do significado profundo. Patrícia da Silva Santos (2016) no livro Sociologia e superfície contribui para uma reabilitação crítica da ideia de superfície. Em sua análise dos escritos de Kracauer, ela mostra como estavam configuradas as ideias de superfície no sentido de uma dedicação sociológica ao estudo do cotidiano. Tendo a raiz no pensamento de Georg Simmel, a ideia de superfície congrega as intenções de conhecer o objeto tomando a aparência imediata como ponto de partida15. Para Santos (2016), as discretas manifestações da superfície são assim

\footnotetext{
${ }^{15}$ No livro Sociologia e superfície - uma leitura dos escritos de Siegfried Kracauer até 1933, Patricia da Silva Santos (2016) realiza uma profunda análise do desenvolvimento do pensamento de Kracauer. Para além do pensamento de Kracauer, subjaz uma presença intelectual da obra de Georg Simmel no pensamento do autor, bem como, de outros intelectuais que foram seus contemporâneos. Pode-se dizer que Kracauer também toma parte da herança simmeliana e, por esse sentido, as teses sobre o conceito de sociologia fazem sentido na reflexão deste artigo, na medida em que, atuam num panorama intelectual comum que corresponde aos escritos de Simmel, Benjamin, Kracauer e Adorno. Em várias passagens a autora analisa o procedimento de escrita de Kracauer, nesse sentido, situando-o numa linhagem de ensaístas que derivam de Simmel. Penso aqui na sugestão da ideia presente em Kracauer de vida como processo em contraposição a ideia fechada de sistema.
} 
"formas marginais" que se expressam de modo ainda não explícito, mas que, carregam consigo um caminho para a apreensão do profundo. Em sua análise sobre Kracauer e o entrelaçamento do olhar sociológico para a superfície e seu vínculo com o sistema capitalista.

\footnotetext{
A sociologia das superficies, como forma de análise da atualidade, adquire sua pertinência nesse sentido: o profundo "esconde-se" nas entranhas mais banais da sociedade contemporânea de modo que cada superfície possuiria uma espécie de referência ao sistema econômico. (SANTOS, 2016, p. 275)
}

Por essa perspectiva, a noção de superfície atua como princípio reflexivo, um primeiro passo para o caminhar do pensamento. Ela não se encerra em si, mas sugere uma origem do pensamento, uma primeira impressão dos fenômenos sociológicos. Podemos dizer que o ensaio tateia um fragmento e, no processo de reflexão do objeto, propõe seus vínculos com outros fragmentos num sentido de visada a totalidade. Algo análogo ao pintor que compõe as paisagens partindo de um detalhe minúsculo e, no processo de descrição, retrata uma totalidade no interior de uma moldura.

Sobre a questão do subjetivismo, ao longo do estudo foram apontados inúmeros contra-argumentos diante tal perspectiva. Embora o ensaísta origine sua reflexão de seu ponto original, isto é, suas impressões, ele confronta tais ideias com a realidade objetiva. Como em Simmel que, o ponto de vista da subjetividade combina-se com da objetividade na criação de um duplo-olhar descrito nas constelações experimentadas pelo ensaísta. O dualismo sociológico de Simmel assume a radicalidade de confrontar as impressões do objeto com uma espécie de vida própria das formas nas quais, cabe ao pensador, acompanhá-las em seu movimento particular.

Novamente fazendo menção ao O ensaio como forma, Adorno contribui para fecharmos essa nota a respeito da ideia de subjetivismo. O aparente "mal-estar" presente nos adversários do ensaio deriva da ideia de que ele se perpetua num exercício infinito. De fato, tal ideia, à luz da tradição que propomos, parece-nos verdadeira. Mas o significado do sempre indefinido alude ao atributo do não estabelecimento do pensamento na rede do sistema. 
Mas esse mal-estar não é verdadeiro, porque a constelação do ensaio não é tão arbitrária quanto pensa aquele subjetivismo filosófico que desloca para a ordem conceitual a coerção própria da coisa. O que determina o ensaio é a unidade de seu objeto, junto com a unidade de teoria e experiência que o objeto acolhe (ADORNO, 2003, p. 36).

Em conclusão, as teses defendidas neste artigo a respeito da forma ensaio, sublinham a existência de uma tradição de pensadores dedicados à investigação do fenômeno moderno que tomaram como mediação procedimental o ensaio. A obra de Georg Simmel se mostrou paradigmática, na medida em que dela foi derivada uma disposição intelectual marcadamente presente em pensadores das ciências do espírito. A herança simmeliana, como vimos, foi reivindicada nas obras de Benjamin, Kracauer e Elias. Para além da ideia de ensaio, o conceito de constelação (ou figuração) atua como uma afinidade eletiva entre as perspectivas teóricas dos pensadores mencionados e se concretiza num programa de pesquisa sociofilosófico de investigação do fenômeno moderno.

\section{Referências}

ADORNO, Theodor. O ensaio como forma. In: Notas de literatura I. São Paulo: Duas Cidades/Ed. 34, 2003.

Caracterização de Walter Benjamin. In: Prismas - crítica e sociedade. São Paulo: Editora Ática. 1998 [1950].

BENJAMIN, Walter. Ursprung des deutschen Trauerspiels. In: Gesammelte Schriften I. Frankfurt am Main: Suhrkamp. 1991 [1925].

Passagens. Belo Horizonte: Editora UFMG, 2018.

BENSE, Max. O ensaio e sua prosa. In: Revista Serrote volume 16. Instituto Moreira Salles, São Paulo, 2014.

ELIAS, Norbert. O processo civilizador. Rio de Janeiro: Jorge Zahar, 1994.

FREUD, Sigmund. O infamiliar [Das Unheimliche]. Belo Horizonte: Autêntica Editora, 2019 .

HORKHEIMER, Max. Teoria tradicional e teoria crítica. Textos escolhidos. São Paulo: Abril Cultural (Os Pensadores), 1980 [1937]. 
. Eclipse da razão. São Paulo: Editora Unesp, 2015 [1947].

KRACAUER, Siegfried. O ornamento da massa: ensaios. São Paulo: Cosac Naify, 2009.

LUKÁCS. Gÿorgy. Sobre a essência e a forma do ensaio: Carta a Leo Popper. In: Revista Serrote volume 18. Instituto Moreira Salles, São Paulo, 2014.

MACHADO, Francisco de Ambrosis Pinheiro. Imanência e história: a crítica do conhecimento em Walter Benjamin. Belo Horizonte: Editora UFMG, 2004.

MONTAIGNE, Michel de. Ensaios. São Paulo: Editora 34, 2016.

NIETZSCHE, Friedrich. O Nascimento da tragédia ou helenismo e pessimismo. São Paulo: Companhia das letras. 2007.

RINGER, Fritz K. O declínio dos Mandarins alemães: A comunidade acadêmica alemã, 1890-1933. São Paulo: Editora Universidade de São Paulo, 2000.

SANTOS, Patrícia da Silva. Sociologia e superfície: uma leitura dos escritos de Siegfried Kracauer até 1933. São Paulo: Unifesp, 2016.

SIMMEL, Georg. Exkurs über den Fremden. In: Soziologie - Untersuchungen über die Formen der Vergesellschaftung. Suhrkamp: Frankfurt am Main. 1992.

As grandes cidades e a vida do espírito (1903). Mana, Rio de Janeiro, v.11, n.2, 2005 .

STAROBINSKI, Jean. É possível definir o ensaio? In: Revista Serrote volume 10. Instituto Moreira Salles, São Paulo, 2012.

SULLIVAN, John Jeremiah. Essai, Essay, Ensaio. In: Revista Serrote volume 19. Instituto Moreira Salles, São Paulo, 2015.

WAIZBORT, Leopoldo. As aventuras de Georg Simmel. São Paulo: Programa de PósGraduação em Sociologia da FFLCH-USP/Editora 34, 2013.

. Elias e Simmel. In: Dossiê Norbert Elias. São Paulo: Universidade de São Paulo, 2001.

WITTE, Bernd. Walter Benjamin. Uma biografia. Belo Horizonte: Autêntica Editora, 2017.

ZWEIG, Stefan. Montaigne e a liberdade espiritual. In: O mundo insone e outros ensaios. Rio de Janeiro: Zahar, 2013. 